\title{
Deliberative assessment of surrogate consent in dementia research
}

\author{
Scott Y. H. Kim ${ }^{\mathrm{a}, \mathrm{b}, \mathrm{c}, *}$, Rebecca A. Uhlmann ${ }^{\mathrm{b}}$, Paul S. Appelbaum ${ }^{\mathrm{d}}$, David S. Knopman ${ }^{\mathrm{e}}$, \\ H. Myra Kim ${ }^{f}$, Laura Damschroder ${ }^{\mathrm{g}}$, Elizabeth Beattie ${ }^{\mathrm{h}}$, Laura Struble ${ }^{\mathrm{i}}$, Raymond De Vries ${ }^{\mathrm{a}}$ \\ ${ }^{a}$ Bioethics Program, University of Michigan, Ann Arbor, MI, USA \\ ${ }^{b}$ Center for Behavioral and Decision Sciences in Medicine, University of Michigan, Ann Arbor, MI, USA \\ ${ }^{c}$ Department of Psychiatry, University of Michigan, Ann Arbor, MI, USA \\ ${ }^{d}$ Division of Law, Ethics, and Psychiatry, Department of Psychiatry, Columbia University and New York State Psychiatric Institute, New York, NY, USA \\ ${ }^{e}$ Department of Neurology, Mayo Clinic, Rochester, MN, USA \\ ${ }^{f}$ Center for Statistical Consultation and Research, University of Michigan, Ann Arbor, MI, USA \\ ${ }^{g}$ Health Services Research and Development, Ann Arbor Veterans Administration Medical Center, Ann Arbor, MI, USA \\ ${ }^{h}$ Dementia Collaborative Research Centre, Queensland University of Technology, Brisbane, Queensland, Australia \\ ${ }^{i}$ Division of Acute, Critical, and Long-Term Care Programs, School of Nursing, University of Michigan, Ann Arbor, MI, USA
}

Abstract

Background: Research involving incapacitated persons with dementia entails complex scientific, legal, and ethical issues, making traditional surveys of layperson views on the ethics of such research challenging. We therefore assessed the impact of democratic deliberation (DD), involving balanced, detailed education and peer deliberation, on the views of those responsible for persons with dementia.

Methods: One hundred and seventy-eight community-recruited caregivers or primary decisionmakers for persons with dementia were randomly assigned to either an all-day DD session group or a control group. Educational materials used for the DD session were vetted for balance and accuracy by an interdisciplinary advisory panel. We assessed the acceptability of family-surrogate consent for dementia research ("surrogate-based research") from a societal policy perspective as well as from the more personal perspectives of deciding for a loved one or for oneself (surrogate and self-perspectives), assessed at baseline, immediately post-DD session, and 1 month after DD date, for four research scenarios of varying risk-benefit profiles.

Results: At baseline, a majority in both the DD and control groups supported a policy of family consent for dementia research in all research scenarios. The support for a policy of family consent for surrogate-based research increased in the DD group, but not in the control group. The change in the DD group was maintained 1 month later. In the DD group, there were transient changes in attitudes from surrogate or self-perspectives. In the control group, there were no changes from baseline in attitude toward surrogate consent from any perspective.

Conclusions: Intensive, balanced, and accurate education, along with peer deliberation provided by democratic deliberation, led to a sustained increase in support for a societal policy of family consent in dementia research among those responsible for dementia patients.

(C) 2010 The Alzheimer's Association. All rights reserved.

Keywords: $\quad$ Alzheimer's disease; Informed consent; Deliberative democracy; Bioethics; Research ethics; Surrogate-based research; Impaired decision-making capacity

\section{Introduction}

Alzheimer's disease (AD) is an incurable and devastating illness, and current treatments are of only modest benefit [1]. The number of persons with $\mathrm{AD}$ worldwide is expected to

*Corresponding author. Tel.: 734-936-5222; Fax: 734-936-8944.

E-mail address: scottkim@umich.edu reach 80.1 million by 2040 [2]. Research on AD can involve invasive procedures with unpredictable risks [3,4]. Although some persons with mild $\mathrm{AD}$ may be able to provide consent, the disease leads to early decisional incapacity $[5,6]$, and surrogate consent for research is usually necessary. Yet the policies regarding the ethics of surrogate consent for dementia research remain unsettled. 
In the United States, regulations allow research with incapacitated adults based on consent by their legally authorized representatives (LARs) (45CFR46, 102c, 111.a4, and 116). However, regulations defer to the states for defining LARs, and few states have done so $[7,8]$. There is no consensus on how much special protection is needed when subjects are enrolled in surrogate-based research (SBR) [9-12]. Three recent state laws (in California, Virginia, and New Jersey) diverged on how to balance potential benefits and risks [8]. The United States federal government is currently revisiting SBR oversight policy [13]. The United Kingdom is also focusing on ethical issues in dementia, including the ethics of SBR [14].

Given the continuing uncertainty and variability in policies for SBR oversight, input from the public is especially important. There have been few attempts to understand the attitudes of the lay public or of stakeholder groups [1518]. We conducted a national survey of older Americans [19] that showed fairly broad support for SBR. However, SBR policy issues involve considerable scientific, regulatory, and ethical complexities. How valid are the cross-sectional opinions of laypersons when they are based on sparse background knowledge regarding such complex issues? If people have an opportunity to learn directly from experts, deliberate with peers, and reflect more on the issues, their considered opinions may be different from their initial responses. These considered ethical opinions would arguably provide a more valid basis for policy-making. Therefore, some advocate that citizen opinions should be obtained using methods based on the concept of deliberative democracy [20], especially for certain bioethics questions, such as research without subject consent [21]. Here, we assessed the impact of democratic deliberation (DD) on the views of one key group, i.e., caregivers and primary decision-makers for persons with dementia, using a randomized experimental design.

\section{Methods}

\subsection{Participants and study sample}

This study was part of a larger DD project on SBR involving caregivers and decision-makers for persons with dementia (the findings presented here) and the general public (in a study still underway). For both subject groups, the primary aim was to elicit attitudes toward societal policy regarding SBR.

Subjects for this study were recruited using the mailing lists of the local Alzheimer Association (AA) and an AD research center, and by advertisements in the University of Michigan research website and in a local AA chapter newsletter. Persons were eligible if they were either caregivers or primary decision-makers for persons with dementia, living or deceased. We conducted two waves of recruitment and two DD sessions, to keep each session small enough for quality control.

\subsection{Procedures}

\subsubsection{Surveys}

Subjects were randomized to either a survey-only group (control group) or to the DD session group (DD group) (Table 1). Both groups completed the study survey three times: 1 month before the DD session date, at the end of the DD day (for DD group) or around that date (by mail, for the control group), and 1 month after the DD date.

\subsubsection{DD procedures}

Two weeks before the DD date, members of the DD group were provided with copies of experts' presentations to be given at the DD session. Participants were asked to read through the presentations before the meeting, and to prepare questions for the experts. Control subjects received only the surveys.

On the day of the DD session, DD group participants were randomly assigned to tables, in groups ranging from 6 to 8 persons per table. There were six groups per session, each with a trained facilitator. The schedule of the day included a plenary introduction; a small group icebreaker exercise; a plenary interactive presentation on "Clinical Research in Alzheimer's Disease," followed by a plenary interactive presentation on "Ethical Issues in Surrogate-Based Research"; a second small group discussion of the two plenary presentations, regarding the arguments for and against SBR in general; a plenary interactive session on the four research scenarios (lumbar puncture study, new drug randomized clinical trial, vaccine study, and gene transfer study; details are given below); and a third, and final, small group discussion, during which participants were asked to reach a group decision, by consensus or majority, for the question, "If patients cannot make their own decisions about being in studies like this one, should our society allow or not allow their families to make the decision in their place?" Groups were also asked to provide their rationale for their responses to the question, "Why should surrogate consent be allowed or not allowed?" To maintain balanced expert responses to all questions, the two experts (the $\mathrm{AD}$ clinical researcher and the bioethicist) traveled together from table to table to answer questions throughout the day.

\subsection{Study materials}

\subsubsection{DD session slide presentations on $A D$ clinical research and on the ethics of $S B R$}

There were two 45-minute PowerPoint presentations during the DD day: one on $\mathrm{AD}$ clinical research, and another on the ethics of SBR (these presentations are available from S.Y.H.K.). These were developed using an iterative process involving experts (D.S.K. for clinical research in $\mathrm{AD}$, and P.S.A. for clinical ethics), the rest of the research team, and members of the project's advisory panel (consisting of a political-science expert in DD methods, a senior $\mathrm{AD}$ researcher, a bioethicist-sociologist, a geriatrician, a director 
Table 1

Comparison of characteristics of subjects in DD group and control group

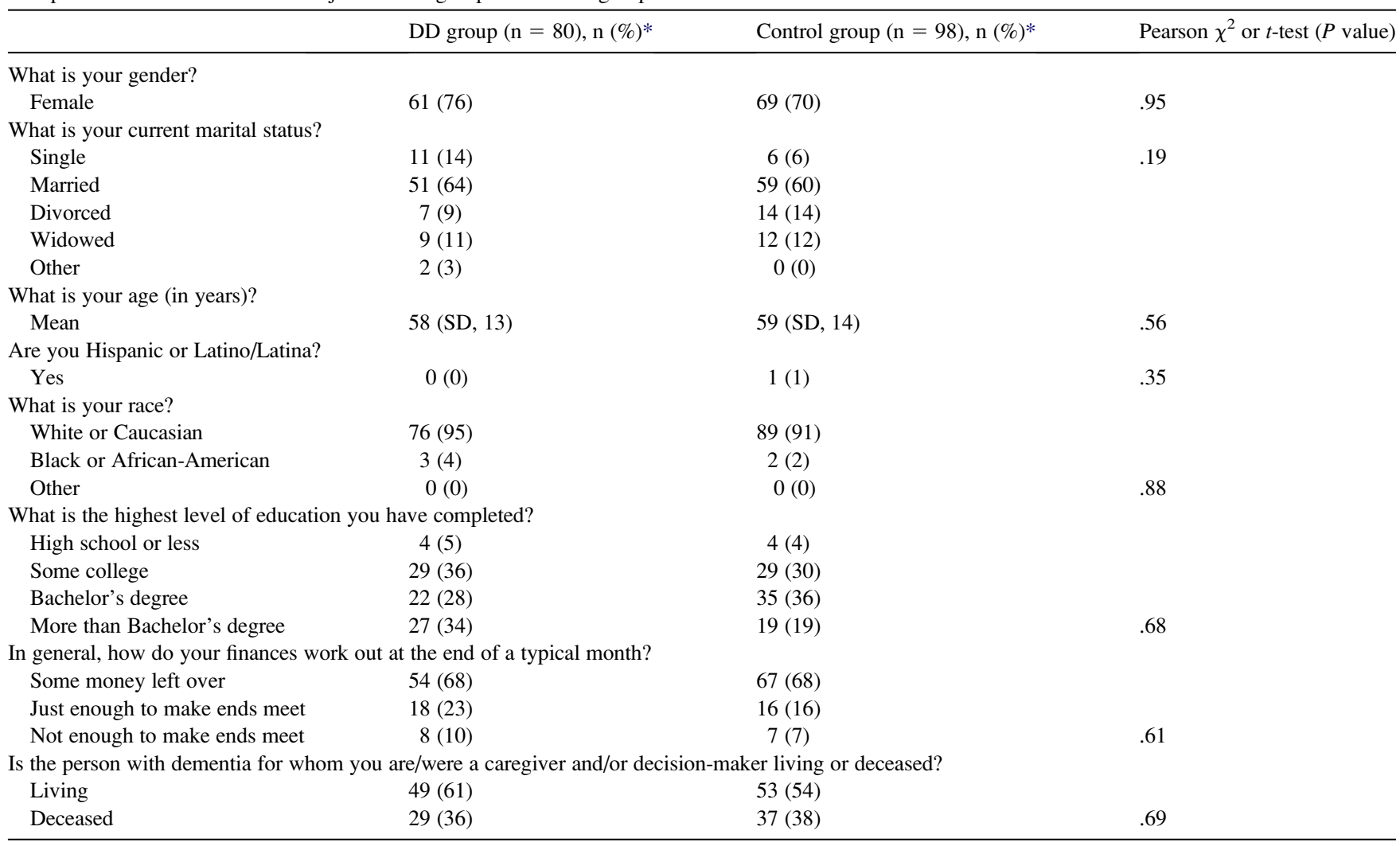

Abbreviation: DD, democratic deliberation.

*Percentages of some variables do not total $100 \%$, because not all respondents chose to answer, or because of rounding.

of human-subject protection programs at an academic medical center, a qualitative research expert, a gerontological nurse, and a caregiver of a person with AD). Numerous revisions were made in successive drafts for the accuracy of statements about the science of AD research and the ethics of SBR, as well as for comprehensibility, clarity, and especially balance.

\subsubsection{Attitudes toward SBR}

Our survey was a shortened version of an earlier instrument that had been validated and used in previous research [15]. The survey began with an introduction to $A D$ and to the ethical dilemma of SBR, and presented four research scenarios of about 120 words each, about which the respondents answered five questions. The four scenarios depict a lumbar puncture (LP) study, a randomized clinical trial (RCT) for a medication, a vaccine trial, and an early-phase gene-transfer trial.

The first three questions elicit attitudes about the acceptability of SBR from three different perspectives: (1) "If patients cannot make their own decisions about being in studies like this one, should our society allow their families to make the decision in their place?" (societal perspective;
Table 2; this societal perspective question most directly assesses the subject's attitude toward SBR as a matter of ethics policy); (2) "Suppose you wanted to give a close family member instructions for the future, in case you ever became unable to make decisions for yourself. Would you say you would want to participate in the study?" (selfperspective; Table 3); and (3) "Suppose you have a loved one who has Alzheimer's disease and cannot make decisions for himself or herself. Would you give permission for your loved one to be part of this study?" (surrogate perspective; Table 4). The response options were: definitely yes, probably yes, probably no, and definitely no. The selfperspective question (question 2) had another question associated with it: "How much freedom or leeway would you give the close family member to go against your preference, and instead [opposite of answer to 2] enroll/ not enroll you in the study?" with response options of no leeway, some leeway, or complete leeway (Table 3). The final question asks respondents to categorize the risks involved in each scenario as minimal (described as "risk of everyday activities"), minor increase over minimal, moderate, or high (Table 5). The survey was written at an 8th grade reading level (Flesch-Kincaid grade level 8.4). 
Table 2

Willingness to allow societal policy of family consent for SBR (societal perspective)

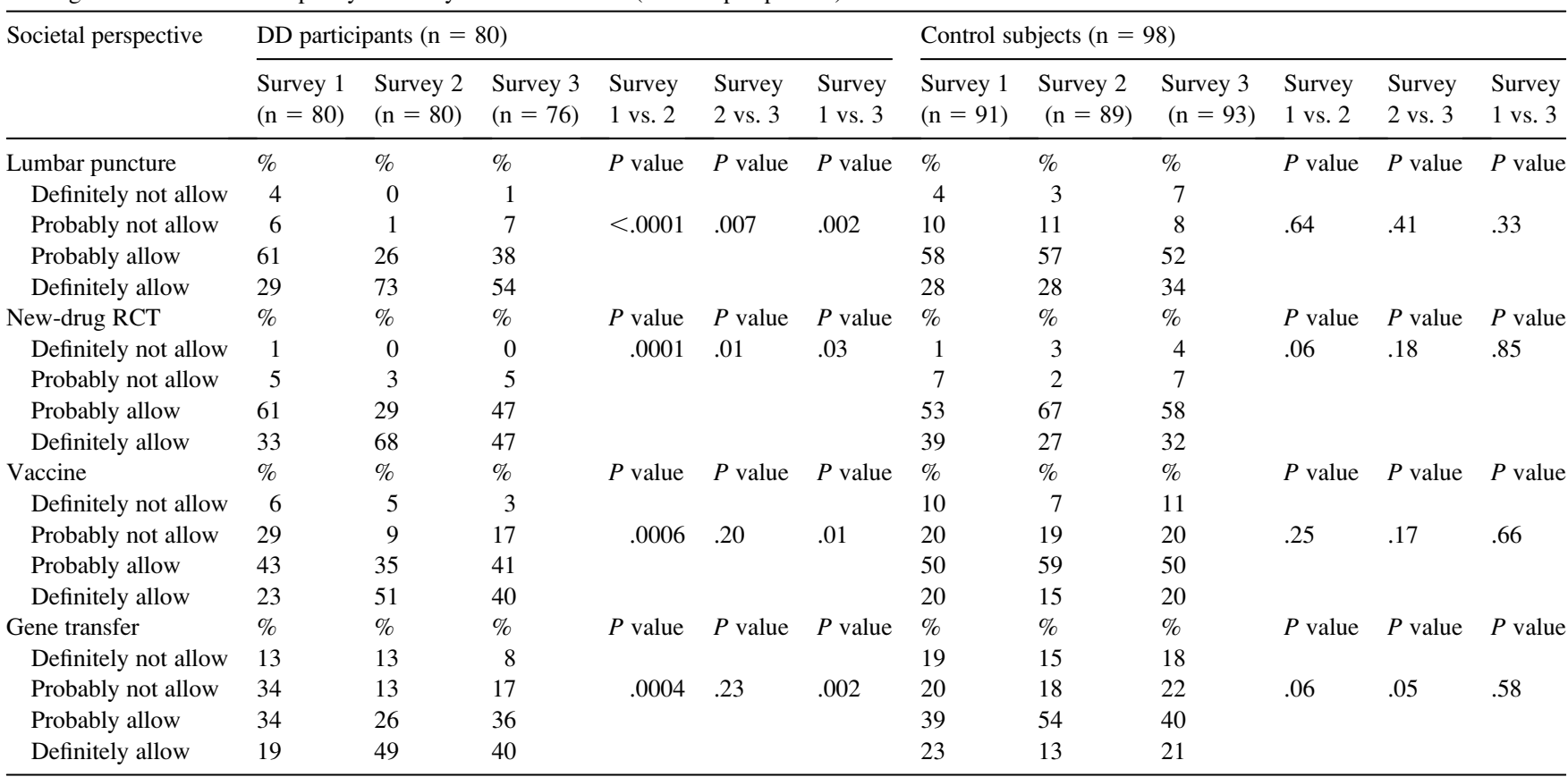

Abbreviations: DD, deliberative democracy; RCT, randomized, controlled trial; SBR, surrogate-based research.

\subsubsection{Demographics and subject characteristics}

Table 1 describes subjects' characteristics.

\subsubsection{Research attitudes questionnaire}

The research attitudes questionnaire (RAQ) is an 11-item scale that assesses participants' general attitudes toward medical research [22]. The five response options range from "strongly agree" to "strongly disagree," with a total score range of 11 to 55, where higher scores indicate a more favorable attitude toward biomedical research.

\subsubsection{DD session day evaluation}

The feedback on the DD session evaluation form (Table 6) contained six questions on a 10-point scale and an open-ended question, "Is there anything about today's session that changed how you think about surrogate-based research?"

\subsection{Analyses}

Personal characteristics between the two study groups were compared using the $\chi^{2}$ test for categorical variables, and a two-sample $t$-test for interval data variables. Withinsubject categorical responses were analyzed using a test of symmetry [23]. Interval data were analyzed using paired $t$-tests for within-subject comparisons. Analyses were conducted using Stata 9.2 (Stata Corp., College Station, TX).

\subsection{Human subjects}

This study was approved by the University of Michigan's Institutional Review Board, and subjects provided verbal informed consent after the procedures had been fully explained.

\section{Results}

We randomized 212 volunteers (103 control subjects, and 109 DD participants). Of the 109 assigned to attend the all-day DD session, 80 (73\%) attended. Of the 103 assigned to the control group, five dropped out without completing any of the surveys, leaving 98 (97\%) who completed at least one survey. All DD group analyses included only those who attended the DD session, and we found no meaningful or statistically significant differences in baseline characteristics between attendees and nonattendees among those assigned to the DD group. Further, the personal characteristics of DD attendees and the final control group were similar (Table 1).

\subsection{Attitudes toward SBR}

Tables 2 through 5 present the responses of the DD group and of the control group regarding attitudes toward SBR. At baseline (survey 1), there were no significant differences between the control group and the DD group for any of the five survey questions regarding attitudes towards the four SBR scenarios, indicating successful randomization. The baseline support for the societal policy of family consent for SBR (combining "probably allow" and "definitely allow") (Table 2) was high, ranging from 53\% support (for the DD group) and 62\% support (for the control group) for the gene-transfer protocol, to $92 \%$ to $94 \%$ support for the newdrug RCT study. For the DD group, there was an increase in support for allowing family consent for SBR when measured just after the DD session (survey 1 vs. survey 2), and 
Table 3

Willingness to participate in SBR and degree of leeway respondents would allow their future surrogates (self-perspective)

\begin{tabular}{|c|c|c|c|c|c|c|c|c|c|c|c|c|}
\hline \multirow[t]{2}{*}{ Self-perspective/leeway } & \multicolumn{6}{|c|}{ DD participants $(\mathrm{n}=80)$} & \multicolumn{6}{|c|}{ Control subjects $(\mathrm{n}=98)$} \\
\hline & $\begin{array}{l}\text { Survey } 1 \\
(\mathrm{n}=80)\end{array}$ & $\begin{array}{l}\text { Survey } 2 \\
(\mathrm{n}=80)\end{array}$ & $\begin{array}{l}\text { Survey } 3 \\
(\mathrm{n}=76)\end{array}$ & $\begin{array}{l}\text { Survey } \\
1 \text { vs. } 2\end{array}$ & $\begin{array}{l}\text { Survey } \\
2 \text { vs. } 3\end{array}$ & $\begin{array}{l}\text { Survey } \\
1 \text { vs. } 3\end{array}$ & $\begin{array}{l}\text { Survey } 1 \\
(\mathrm{n}=91)\end{array}$ & $\begin{array}{l}\text { Survey } 2 \\
(\mathrm{n}=89)\end{array}$ & $\begin{array}{l}\text { Survey } 3 \\
(\mathrm{n}=93)\end{array}$ & $\begin{array}{l}\text { Survey } \\
1 \text { vs. } 2\end{array}$ & $\begin{array}{l}\text { Survey } \\
2 \text { vs. } 3\end{array}$ & $\begin{array}{l}\text { Survey } \\
1 \text { vs. } 3\end{array}$ \\
\hline Lumbar puncture & $\%$ & $\%$ & $\%$ & $P$ value & $P$ value & $P$ value & $\%$ & $\%$ & $\%$ & $P$ value & $P$ value & $P$ value \\
\hline Self: definitely no & 1 & 0 & 1 & & & & 3 & 1 & 5 & & & \\
\hline Self: probably no & 12 & 6 & 9 & .02 & .03 & .40 & 17 & 13 & 16 & .78 & .42 & .61 \\
\hline Self: probably yes & 49 & 38 & 50 & & & & 44 & 52 & 48 & & & \\
\hline Self: definitely yes & 38 & 56 & 40 & & & & 36 & 35 & 30 & & & \\
\hline Leeway: none & 30 & 16 & 16 & & & & 33 & 17 & 30 & & & \\
\hline Leeway: some & 56 & 63 & 61 & .02 & .37 & .02 & 51 & 66 & 60 & .01 & .01 & .14 \\
\hline Leeway: complete & 14 & 21 & 24 & & & & 17 & 17 & 10 & & & \\
\hline New-drug RCT & $\%$ & $\%$ & $\%$ & $P$ value & $P$ value & $P$ value & $\%$ & $\%$ & $\%$ & $P$ value & $P$ value & $P$ value \\
\hline Self: definitely no & 1 & 0 & 1 & & & & 2 & 1 & 1 & & & \\
\hline Self: probably no & 9 & 4 & 7 & .02 & .07 & .70 & 11 & 8 & 9 & .19 & .90 & .62 \\
\hline Self: probably yes & 46 & 38 & 51 & & & & 48 & 54 & 51 & & & \\
\hline Self: definitely yes & 44 & 59 & 41 & & & & 39 & 37 & 39 & & & \\
\hline Leeway: none & 30 & 19 & 18 & & & & 33 & 23 & 27 & & & \\
\hline Leeway: some & 55 & 61 & 59 & .10 & .66 & .12 & 52 & 64 & 63 & .10 & .39 & .03 \\
\hline Leeway: complete & 15 & 20 & 22 & & & & 14 & 14 & 10 & & & \\
\hline Vaccine & $\%$ & $\%$ & $\%$ & $P$ value & $P$ value & $P$ value & $\%$ & $\%$ & $\%$ & $P$ value & $P$ value & $P$ value \\
\hline Self: definitely no & 13 & 11 & 9 & & & & 10 & 11 & 15 & & & \\
\hline Self: probably no & 29 & 24 & 31 & .80 & .58 & .27 & 40 & 37 & 34 & .57 & .79 & .58 \\
\hline Self: probably yes & 40 & 41 & 36 & & & & 36 & 37 & 38 & & & \\
\hline Self: definitely yes & 19 & 24 & 24 & & & & 14 & 15 & 13 & & & \\
\hline Leeway: none & 35 & 24 & 22 & .07 & .22 & .06 & 36 & 36 & 40 & .12 & .71 & .26 \\
\hline Leeway: some & 54 & 63 & 61 & & & & 52 & 53 & 52 & & & \\
\hline Leeway: complete & 11 & 14 & 17 & & & & 12 & 11 & 8 & & & \\
\hline Gene transfer & $\%$ & $\%$ & $\%$ & $P$ value & $P$ value & $P$ value & $\%$ & $\%$ & $\%$ & $P$ value & $P$ value & $P$ value \\
\hline Self: definitely no & 20 & 27 & 24 & & & & 26 & 21 & 19 & & & \\
\hline Self: probably no & 32 & 19 & 32 & .61 & .31 & .63 & 30 & 33 & 34 & .49 & .78 & .17 \\
\hline Self: probably yes & 32 & 40 & 28 & & & & 28 & 33 & 35 & & & \\
\hline Self: definitely yes & 17 & 14 & 17 & & & & 17 & 14 & 12 & & & \\
\hline Leeway: none & 39 & 34 & 36 & & & & 52 & 38 & 41 & & & \\
\hline Leeway: some & 51 & 49 & 49 & .21 & .80 & .39 & 36 & 51 & 51 & .03 & .57 & .01 \\
\hline Leeway: complete & 10 & 18 & 16 & & & & 12 & 11 & 9 & & & \\
\hline
\end{tabular}

Abbreviations: DD, deliberative democracy; RCT, randomized, controlled trial; SBR, surrogate-based research.

this change remained significant 1 month after the DD session (survey 1 vs. survey 3 ) for all four research scenarios. For control subject, no sustained changes were evident from baseline to 1 month after the DD session in attitudes toward family consent for SBR as a social policy.

In terms of whether one would participate in SBR (Table 3 ), the attitude of the DD group became more favorable just after the DD session for the lower-risk scenarios (LP and new-drug RCT scenarios), but not for the higher-risk vaccine and gene-transfer scenarios. These changes were not sustained 1 month later. The DD group became more favorable toward allowing leeway to their surrogates for the LP scenario and possibly for the vaccine scenario, and this attitude was sustained at 1 month. For control subjects, there were no changes in the self-perspective and small, sustained changes in leeway responses for the RCT and gene-transfer scenarios.

With regard to whether one would enroll a loved one in SBR (i.e., responding from the surrogate's perspective; Table 4), the DD group became more favorable toward enrolling a loved one in SBR for the LP, RCT, and vaccine scenarios (but not for gene transfer) just after the DD session, but none of these changes were sustained 1 month later. For the control group, there were no changes in attitude across the three surveys on this question.

In terms of perception of risk (Table 5), there were no significant changes in the DD session group's perception of level of risk for the drug RCT, vaccine, and gene-transfer scenarios across the three surveys. For the LP scenario, the postDD session survey showed a decrease in perception of risk, and by 1 month after the session, there appeared to be a polarization in the group, i.e., a decrease in the middle level (minor increase over minimal risk), but an increase in the minimalrisk and moderate-risk responses.

The general attitude toward biomedical research (RAQ) scores (scale range, 11 to 55) changed from 41.1 (SD, 4.0) at baseline to 42.1 (SD, 3.9) to 41.8 (SD, 4.0) for the DD group. Although the change was statistically significant (paired $t$-test for surveys 1 and $3, P=0.03$ ), its magnitude was very small. For the control group, the RAQ scores were 41.8 (SD, 4.1), 41.7 (SD, 4.0), and 42.1 (SD, 4.4); these were not statistically different. 
Table 4

Willingness to allow participation of a loved one in SBR, when acting as a surrogate (surrogate perspective)

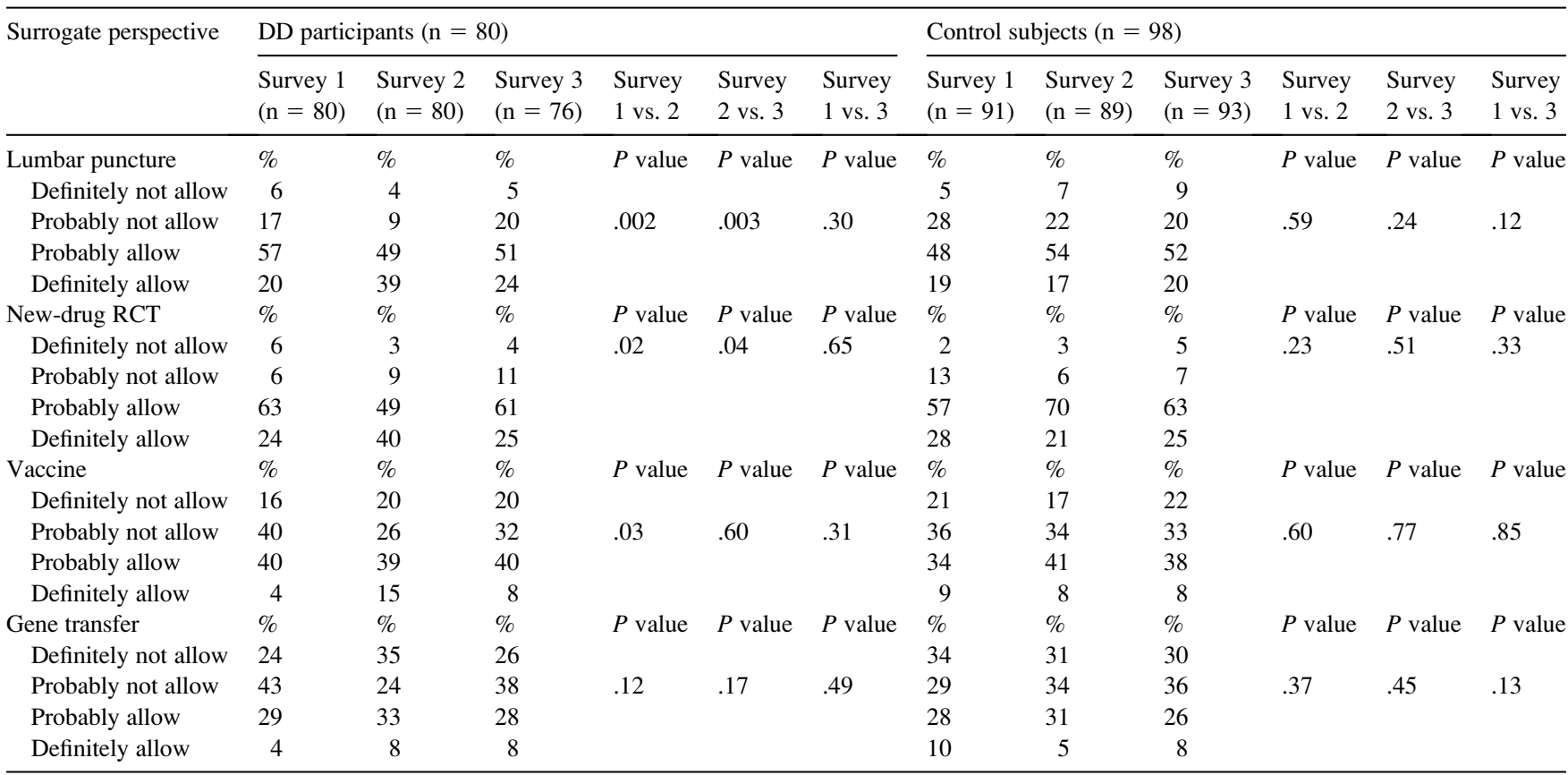

Abbreviations: DD, deliberative democracy; RCT, randomized, controlled trial; SBR, surrogate-based research.

\subsection{Perceptions of $D D$ session}

Participants in the DD session had a very positive view of their experience, as indicated by responses to the questions in Table 6 . Nearly $90 \%$ of respondents were willing (to varying degrees) to abide by the policy decision put forward by their small group. Seventy-two of 80 attendees provided comments when asked, "Is there anything about today's session that changed how you think about surrogate-based research?" Of these, 58\% (42/72) were general comments about the session (e.g., "Everything was great!" or "Make it longer"), and not specific answers to the question. The remaining responses commented on an increase in knowledge ("By receiving an explanation of the rationale behind research, I became better informed to make a decision. It was helpful to have 'the experts' answering questions and providing background information."), the benefits of deliberation ("Listening/ discussing several viewpoints helped clarify my opinions rather than specifically changing them."), the broadening of frameworks ("Thinking about the issues from a societal instead of personal perspective was a different way to think of research benefits/detriments."), and a greater appreciation for the complexity of the issues ("I came in with a mindset that it could be easily handled by a POA [power of attorney]... and realized the issues are much more complex.").

\section{Discussion}

\subsection{Principal findings}

Surrogate-based research entails enrolling persons in research who are incapable of providing their own informed consent. Given that this is a particularly vulnerable group, policies should be based on solid data. Because of the scientific, legal, and ethical complexities of the topic, we provided our respondents balanced, detailed information and a chance to deliberate the issues with lay peers. The DD group became more supportive of SBR from a societal perspective, and this change was sustained even after 1 month. Because the baseline support was already high, this change resulted in very high support (ranging from $76 \%$ for a gene-transfer scenario, to $94 \%$ for a drug RCT) for a societal policy allowing SBR. Although a transient increase occurred in the acceptance of SBR from surrogate and self-perspectives in the lower-risk studies (LP and RCT scenarios), these increases were not sustained. Further, the change in attitude toward SBR policy was not generally accompanied by a change in risk level perceived by subjects, and neither was there an increase in favorable attitude toward biomedical research in general. Thus, the sustained change was quite specific for allowing SBR from a societal perspective.

\subsection{Strengths and weaknesses of the study}

This study had specific strengths. Our experimental design was successful, insofar as the control group and DD group were not different in terms of personal characteristics, and did not differ in their initial attitudes toward SBR. Second, the quality of deliberative sessions was high, as reflected in the level of engagement and the comments in the self-report feedback. We believe there is good reason to believe that the post-DD session opinions of our DD group were more informed, thoughtful, and considered than opinions solicited 
Table 5

Perception of risk level in four research scenarios

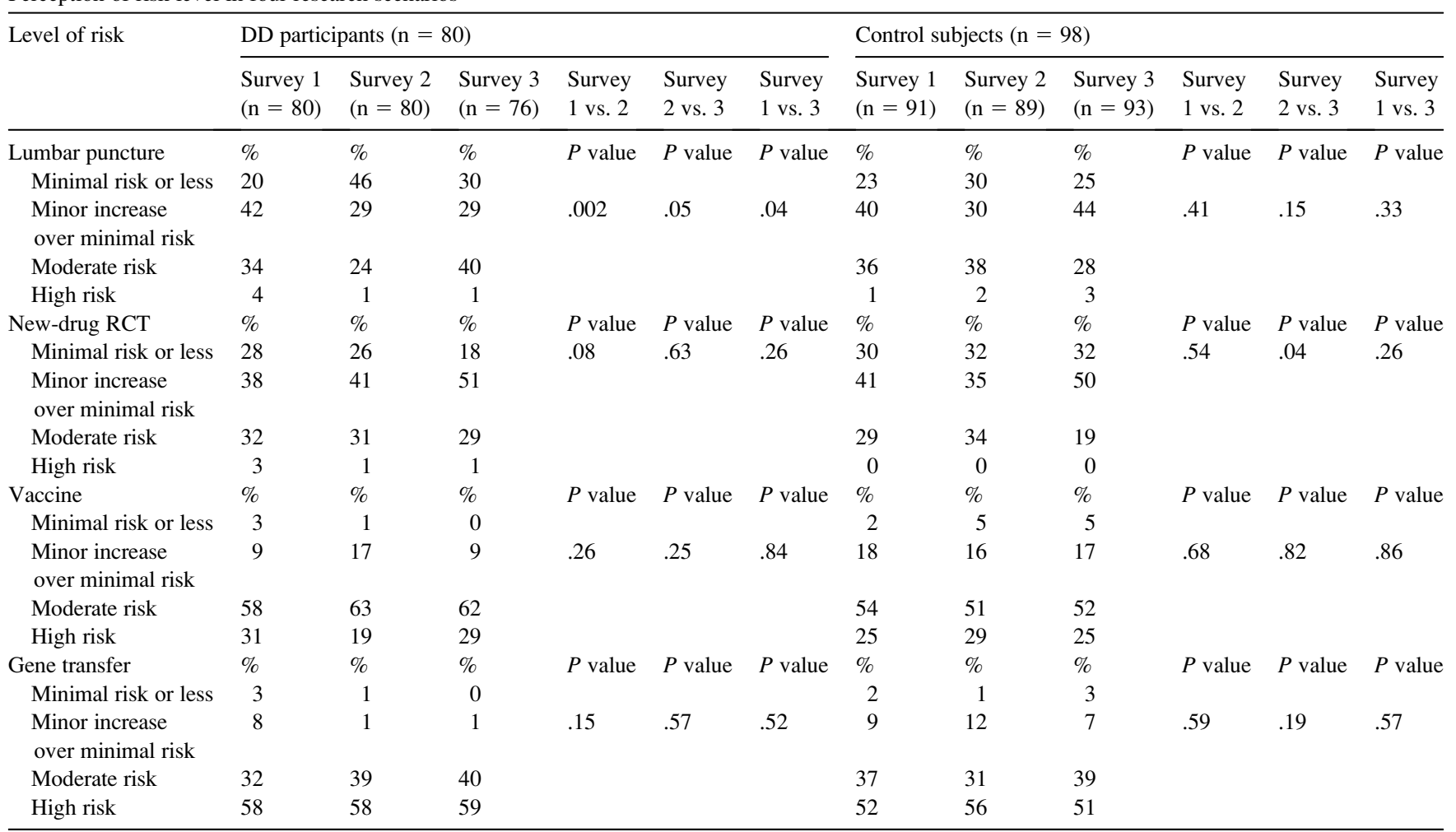

Abbreviations: DD, deliberative democracy; RCT, randomized, controlled trial.

via traditional surveys. In addition, over $90 \%$ of DD participants were willing to abide by policy positions resulting from small group deliberations.

In terms of our study's limitations, although the internal validity was high, external validity was limited by our self-selected sample. However, AD research tends to rely on similarly self-selected samples [24], and that the caregiver/decision-maker samples recruited for this study are highly relevant to the overall debate, because these are the persons likely to function as research surrogates. Second, we did not examine the mechanisms of effect, i.e., whether education or deliberation caused the changes. Based on the self-report feedback, we think that peer-group discussions and interactive learning from expert presentations (as well as experts' availability throughout the day) played a greater role than did simply having the written materials available. Finally, our conclusions cannot be generalized to other settings, such as research in intensive care units.

\subsection{Comparison with previous studies}

Although DD has been used for other research ethics questions $[25,26]$, no studies have used DD methods to assess laypersons' perspectives on SBR ethics. However, the results of our baseline survey, indicating broad support for SBR, are consistent with several previous surveys indicating generally favorable views of SBR in persons at high risk for AD enrolled in a prevention trial [15], in a national survey of Amer- ican older adults [19], in relatives of dementia patients [17], and in elderly clinic patients and senior-center patrons [18]. Our results suggest that this generally favorable view of SBR (at least from a societal policy perspective) will increase even further as respondents receive balanced and detailed education, and an opportunity to deliberate with peers.

\subsection{Meaning and implications of the study}

Our subjects' support for SBR increased from a policy (i.e., societal) perspective, but not from a personal or

Table 6

Perception of DD session by participants $(\mathrm{n}=79)$

\begin{tabular}{|c|c|}
\hline Question & Score range, $1-10(\mathrm{SD})$ \\
\hline $\begin{array}{l}\text { 1. Do you feel that your opinions were } \\
\text { respected by your group? }\end{array}$ & $9.4(1.0)$ \\
\hline $\begin{array}{l}\text { 2. Do you feel that the process that led to your } \\
\text { group's responses was fair? }\end{array}$ & $9.7(0.7)$ \\
\hline $\begin{array}{l}\text { 3. How willing are you to abide by the group's } \\
\text { final position, even if you personally have } \\
\text { a different view? }\end{array}$ & $8.4(2.0)^{*}$ \\
\hline $\begin{array}{l}\text { 4. How helpful did you find each of the } \\
\text { following? }\end{array}$ & \\
\hline Question and answer interaction with experts. & $9.5(0.9)$ \\
\hline The formal presentations given by the experts. & $9.5(1.1)$ \\
\hline $\begin{array}{l}\text { Discussing the issues with other people in } \\
\text { similar situation as yours. }\end{array}$ & $9.4(1.2)$ \\
\hline
\end{tabular}

Abbreviation: DD, deliberative democracy.

* Of 79 respondents, 70 (89\%) were willing, and 9 (11\%) were not. 
surrogate perspective. It is important to bear in mind the significance of each perspective in interpreting the findings [19]. Responses from a societal policy perspective and the more personal perspectives (surrogate and self perspectives) are closely related, but should not be treated as equivalent. Personal willingness to participate, or willingness to enroll a loved one in research, is not a proxy for views about the ethical appropriateness of SBR, because many people may choose not to participate or enroll a loved one in research for a variety of reasons that have nothing to do with ethics. If the point is to characterize public opinion on the ethical permissibility of SBR, then respondents' views from a societal perspective are primary.

We speculate that a sustained change in societal policy attitudes, without a sustained change from the self or surrogate perspectives, may be attributed to two factors. First, deciding from a surrogate or a self-perspective may feel more personal and concrete, and may engage the emotions to a greater degree than considering a societal policy, and therefore attitudes may be less malleable. The societal perspective requires a more intellectual understanding of somewhat abstract societal goods to be balanced against individual interests, and may be more susceptible to change via information and deliberation. As one of our participants stated, "Intellectually I understand the need to have the research done and believe that this is the only way to find out more about the illness and to bring about some real progress. Okay. I support that; I really do. Emotionally speaking, I don't think I could bear to see my mother suffer." Second, the DD session gave our participants an opportunity to take up the perspective of societal policy-making, which is a relatively novel perspective for most people. Hence their initial and final responses from that perspective may have been more open to change. We believe that such a change indicates a positive effect, insofar as some DD theorists argue that one desirable function of democratic deliberation is to "encourage public-spirited perspectives on public issues" [20].

But does the lack of change in personal and surrogate perspectives signal something that is ethically worrisome? We think not. First, the baseline willingness to participate in research from the self-perspective is quite high, comparable to participants' societal perspective responses. Thus, fundamentally, our respondents are not trying to get a "free ride" by shifting burdens onto others. The fact that their societal perspective answers changed, while their self-perspective responses did not, demonstrates that they gained a new appreciation for the societal perspective, rather than a retreat into a more selfish perspective. Second, our respondents were clearly less willing to enroll their loved ones in research, compared with their willingness to enter research themselves or to support a societal policy of family consent. This should be seen as a reassuring result. We should anticipate and accept the cautious and conservative approach that family members will take in enrolling their decisionally incapable loved ones in research.
Our study contains two main implications. First, it is feasible to create forums for democratic deliberation to obtain high-quality input from the lay public on policy issues that involve moral disagreement or uncertainty, as is typical in bioethics. This may be particularly useful when the ethical issue is not widely discussed, and is scientifically and conceptually complex.

The primary implication of our study is that broad support for allowing SBR from a societal perspective will significantly increase with further education and deliberation. A dramatic example involves the gene-transfer scenario, which began with 53\% support. Even 1 month after the DD session, support stood at $76 \%$, a substantial difference. This finding suggests that societal support for SBR, if elicited after educated deliberation, would be higher than for cross-sectional surveys, and may imply that traditional surveys underestimate the level of support that may be attained after deeper ethical reflection by citizens.

\section{Acknowledgments}

Michael Neblo served as political-science consultant. John Creswell served as qualitative-research methodology consultant. Sid Gilman, Roger Tyslan, and Gary Chadwick contributed to the development of study materials. S.Y.H.K. is a Greenwall Foundation Faculty Scholar in Bioethics. The project was supported with additional funding by grant R01-AG029550 from the National Institute on Aging. This study's contents are solely the responsibility of the authors, and do not necessarily represent the official views of the National Institutes of Health.

\section{References}

[1] Clark CM, Karlawish JHT. Alzheimer disease: current concepts and emerging diagnostic and therapeutic strategies. Ann Intern Med 2003;138:400-10.

[2] Ferri C, Prince M, Brayne C, Brodaty H, Fratiglioni L, Ganguli M, et al. Global prevalence of dementia: a Delphi Consensus Study. Lancet 2005;366:2112-7.

[3] Orgogozo JM, Gilman S, Dartigues JF, Laurent B, Puel M, Kirby LC, et al. Subacute meningoencephalitis in a subset of patients with AD after Aß42 immunization. Neurology 2003;61:46-54.

[4] Tuszynski MH, Thal L, Pay M, Salmon DP, Hoi S, Bakay R, et al. A phase 1 clinical trial of nerve growth factor gene therapy for Alzheimer disease. Nat Med 2005;11:551-5.

[5] Okonkwo O, Griffith HR, Belue K, Lanza S, Zamrini EY, Harrell LE, et al. Medical decision-making capacity in patients with mild cognitive impairment. Neurology 2007;69:1528-35.

[6] Kim SYH, Caine ED, Currier GW, Leibovici A, Ryan JM. Assessing the competence of persons with Alzheimer's disease in providing informed consent for participation in research. Am J Psychiatry 2001; 158:712-7.

[7] Hoffmann D, Schwartz J. Proxy consent to participation of the decisionally impaired in medical research-Maryland's policy initiative. J Health Care Law Policy 1998;1:123-53.

[8] Saks E, Dunn L, Wimer J, Gonzales M, Kim S. Proxy consent to research: legal landscape. Yale J Health Law Policy Ethics 2008;8:37-78. 
[9] National Bioethics Advisory Commission. Research involving persons with mental disorders that may affect decisionmaking capacity, volume 1. Rockville, MD: National Bioethics Advisory Commission; 1998.

[10] Maryland Attorney General's Research Working Group. Final report of the Attorney General's Research Working Group. Baltimore, MD: Office of the Maryland Attorney General; 1998.

[11] New York Department of Health Advisory Work Group on Human Subject Research Involving the Protected Classes. Recommendations on the oversight of human subject research involving the protected classes. Albany, NY: State of New York Department of Health; 1999.

[12] Kim SYH, Appelbaum PS, Jeste DV, Olin JT. Proxy and surrogate consent in geriatric neuropsychiatric research: update and recommendations. Am J Psychiatry 2004;161:797-806.

[13] Office of Human Research Protections. Request for information and comments on research that involves adult individuals with impaired decision-making capacity. Fed Reg 2007;72:50966-70.

[14] Nuffield Council on Bioethics. Dementia: ethical issues (consultation paper). London: Nuffield Council on Bioethics, 2008.

[15] Kim SYH, Kim H, McCallum C, Tariot P. What do people at risk for Alzheimer's disease think about surrogate consent for research? Neurology 2005;65:1395-401.

[16] Bravo G, Paquet M, Dubois MF. Opinions regarding who should consent to research on behalf of an older adult suffering from dementia. Int J Soc Res Pract 2003;2:49-65.

[17] Wendler D, Martinez RA, Fairclough D, Sunderland T, Emanuel E. Views of potential subjects toward proposed regulations for clinical research with adults unable to consent. Am J Psychiatry 2002;159:585-91.
[18] Karlawish J, Rubright J, Casarett D, Cary M, Ten Have T, Sankar P. Older adults' attitudes toward enrollment of non-competent subjects participating in Alzheimer's research. Am J Psychiatry 2009; 166:182-8.

[19] Kim S, Kim H, Langa K, Karlawish J, Knopman D, Appelbaum P. Surrogate consent for dementia research: a national survey of older Americans. Neurology 2009;72:149-55.

[20] Fishkin JS. Beyond polling alone: the quest for an informed public. Crit Rev 2006;18:157-65.

[21] Gutmann A, Thompson D. Deliberating about bioethics. Hastings Cent Rep 1997;27:38-41.

[22] Muroff JR, Hoerauf SL, Kim SYH. Is psychiatric research stigmatized? An experimental survey of the public. Schizophr Bull 2006; 32:129-36.

[23] Spieldman RS, McGinnis RE, Ewens WJ. Transmission test for linkage disequilibrium: the insulin gene region and insulin-dependence diabetes mellitus. Am J Hum Genet 1993;52:506-16.

[24] Schneider LS, Olin JT, Lyness SA, Chui HC. Eligibility of Alzheimer's disease clinic patients for clinical trials. J Am Geriatr Soc 1997; 45:923-8.

[25] Damschroder L, Pritts J, Neblo M, Kalarickal R, Creswell JW, Hayward R. Patients, privacy and trust: patients' willingness to allow researchers to access their medical records. Soc Sci Med 2007; 64:223-35.

[26] Secko DM, Preto N, Niemeyer S, Burgess MM. Informed consent in biobank research: a deliberative approach to the debate. Soc Sci Med 2009;68:781-9.

\section{Did you know?}

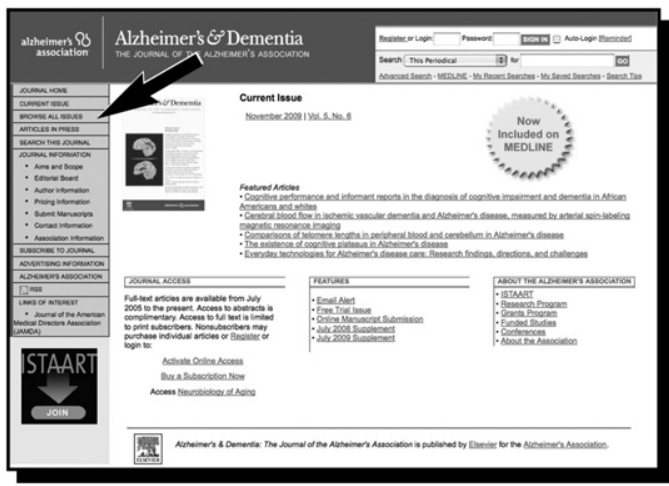

You can access back issues of Alzheimer's \& Dementia online. 